\title{
REGISTRO DE MUDANÇAS AMBIENTAIS PLEISTOCÊNICAS E HOLOCÊNI- CAS EM DEPÓSITOS DE CABECEIRA DE VALE: CAMPO ALEGRE, PLANALTO NORTE CATARINENSE (SC)
}

\author{
MARCELO ACCIOLY TEIXEIRA DE OLIVEIRA ${ }^{1}$, LUIZ CARLOS RUIZ PESSENDA ${ }^{2}$, \\ HERMANN BEHLING ${ }^{3}$, GISELE LEITE DE LIMA ${ }^{4} \&$ GLAUCIA MARIA DOS SANTOS \\ SILVA FERREIRA ${ }^{5}$
}

\begin{abstract}
Resumo A baixa resolução do registro sedimentar continental é a principal fonte de ceticismo em relação à aplicação da geomorfologia e da sedimentologia aos estudos do Quaternário. No entanto, quando apoiadas em dados representativos (proxy data), a geomorfologia e a sedimentologia podem favorecer interpretações paleoambientais. Este trabalho apresenta resultados obtidos a partir de seqüências pedoestratigráficas localizadas em cabeceiras de vale, em planalto do Sul do Brasil. Resultados geomorfológicos, micromorfológicos, sedimentológicos, isotópicos, palinológicos e geocronológicos indicam mudanças ambientais cujas idades coincidem com os Estágios Isotópicos Marinhos (EIM) 5b; 3; 2 e 1. Durante o final do Pleistoceno, o registro indica temperaturas e precipitações abaixo das atuais. Apesar disso, as cabeceiras de vale mantinham ambientes locais relativamente úmidos, alimentados por zonas de saturação de água nos solos que teriam contribuído para a erosão e a sedimentação durante períodos de mudanças climáticas. Durante o Holoceno Médio, depósitos de fluxos torrenciais sugerem clima mais seco do que o atual, com padrão sazonal contrastado, influenciando pulsos de escoamento superficial sobre encostas. O predomínio, nas seqüências, de depósitos relacionados ao escoamento superficial sugere ambiente no qual a precipitação acumulada teria sido mais importante do que as taxas de evaporação. Essa condição paleoidrológica parece ser recorrente e explica de forma satisfatória como as formas de relevo teriam influenciado períodos de pedogênese e de sedimentação na área do estudo em função de mudanças ambientais.
\end{abstract}

Palavras-chave: Geomorfologia, Cabeceiras de Vale, Paleoidrologia, Mudanças Ambientais.

\begin{abstract}
PLEISTOCENIC AND HOLOCENIC ENVIRONMENTAL CHANGES IN THE RECORD OF VALLEY HEAD DEPOSITS: CAMPO ALEGRE, NORTHERN SANTA CATARINA STATE PLATEAU (SC). Low resolution of continental sedimentary record is a common source of skepticism about the application of geomorphology and sedimentology to Quaternary studies. However, when supported by independent proxy data, geomorphology and sedimentology favor palaeoenvironmental interpretation. This paper presents results obtained from pedostratigraphic sequences, in valley head sites of southern Brazilian highlands, based on geomorphological, micromorphological, sedimentological, isotopical and palynological data. Results point to environmental changes, which ages coincide with Marine Isotopic Stages (MIS) 5b; 3; 2 and 1. During the late Pleistocene, in spite of temperatures and precipitation lower than today, the local valley head record points to wetter local environments, where shallow soil-water saturated zones contributed to erosion and sedimentation during periods of climatic change. During the mid Holocene, slope wash deposits suggest a climate drier than today, under the influence of seasonally contrasted precipitation regimes and torrential overland flow on hillslopes. The predominance of overland flow-related sedimentary deposits suggests an excess of precipitation over evaporation influencing local palaeohydrology. This palaeohydrological condition seems to be recurrent and explains how slope morphology had influenced pedogenesis and sedimentation in the study area, in response to environmental changes.
\end{abstract}

Keywords: Geomorfology, Valley Heads, Palaeohydrology, Environmental Changes.

INTRODUÇÃO Características dinâmicas e evolutivas de cabeceiras de vale foram enfatizadas na década de 1990, colocando em evidência unidades do relevo nas quais mecanismos de produção e de preservação de sedimentos tendem a ser recorrentes ao longo do tempo (Dietrich \& Dunne 1993). Todavia, a recorrência de processos erosivo-deposicionais em cabeceiras de vale já havia sido ressaltada na década de 1970 por estudos geomorfológicos conduzidos no Brasil, centrados nas chamadas rampas coluviais (Meis \& Machado 1978, Meis \& Moura 1984). Uma das principais contribuições desses trabalhos pioneiros no Brasil foi a de ressaltar o fato de que mudanças ambientais quaternárias poderiam deixar registros geomorfológicos e sedimentológicos em áreas continentais tropicais e subtropicais.
Coberturas coluviais são relativamente comuns ao longo do Brasil tropical e subtropical (Melo \& Cuchierato 2004), entretanto a escassez de dados representativos a elas associados faz com que poucas áreas no Brasil tenham sido capazes de demonstrar claramente a relação entre a evolução do relevo e eventos relacionados a mudanças climáticas globais (por exemplo, Servant et al. 1989, Turcq et al. 1997, Stevaux \& Santos 1998, Modenesi-Gauttieri 2000). Ao problema da escassez e da baixa resolução do registro quaternário continental (Thomas \& Thorp, 1996; Thomas et al. 2001) acresce o fato de que colúvios são, em geral, depósitos mal organizados, oriundos de fluxos efêmeros que não geram estruturas bem definidas (Bertran \& Texier 1999, Nemec \& Kazanci 1999, Bertran \& Jomeli 2000).

1 - Departamento de Geociências, CFH, Universidade Federal de Santa Catarina (UFSC), maroliv@cfh.ufsc.br, Caixa Postal 5175, cep: 88040-970, Trindade, Florianópolis, Santa Catarina

2 - Centro de Energia Nuclear na Agricultura, Laboratório de C 14, Universidade de São Paulo (USP), pessenda@cena.usp.br, Avenida Centenário no. 303, São Dimas, cep: 13416000, Piracicaba, São Paulo

3 - Departamento de Palinologia e Dinâmica Climática Albrecht-von-Haller, Instituto de Ciências Vegetais, Universidade de Göttingen, hbehling@online.de, Untere Karspüle 237.073, Göttingen, Alemanha

4 - Departamento de Geociências, CFH, Universidade Federal de Santa Catarina (UFSC), glima5@yahoo.com, Caixa Postal 1081, Centro, cep: 88010-970, Florianópolis, Santa Catarina

5 - Departamento de Geociências, CFH, Universidade Federal de Santa Catarina (UFSC), glaucia2506@yahoo.com.br, Rua José Emílio de Souza, n. 67, apt. 102, cep: 88067-110, Nossa Senhora do Rosário, São José, Santa Catarina 
Neste trabalho apresentamos estudo sobre coberturas alúvio-coluviais em cabeceiras de vale, em áreas de planalto do Sul do Brasil. Resultados geomorfológicos, sedimentológicos, palinológicos, isotópicos e micromorfológicos são associados, buscando a interpretação paleoambiental. Os resultados obtidos indicam mudanças ambientais locais que coincidem com eventos climáticos relacionados ao último ciclo glacial e à passagem para o Holoceno.

A área do estudo está situada no município de Campo Alegre, no Estado de Santa Catarina, Brasil, na localidade denominada Cerro do Touro (Fig. 1). O município de Campo Alegre se localiza no Planalto de São Bento do Sul, caracterizado por relevo de colinas que se desenvolvem sobre patamares estruturais. O embasamento local é formado por rochas neoproterozóicas da bacia vulcano-sedimentar de Campo Alegre, representadas na área por traquitos, riolitos e ignimbritos (Biondi et al. 2001). Como a alteração dessas rochas deu origem a importantes jazidas de argila, a morfogênese quaternária local talvez tenha sido influenciada pelos espessos mantos de alteração que, somados a colúvios, aluviões e solos, compõem formações superficiais variadas.

As altitudes locais variam de 850 a 1.046 metros, e o clima é mesotérmico, com verões relativamente frescos (tipo $\mathrm{Cfb}$ de Köppen). A temperatura média anual é de $16,4^{\circ} \mathrm{C}$, e as precipitações médias oscilam entre 1.600 e $1.800 \mathrm{~mm}$. A vegetação tropical e a subtropical coexistem na área, formando a Floresta Ombrófila Mista. Campos de Altitude são comuns, com matas de galeria ocupando vales e depressões topográficas. Estudos geomorfológicos preliminares desenvolvidos na área revelaram rico registro quaternário continental, composto principalmente de paleossolos e de estruturas sedimentares alúvio-coluviais bem preservadas, em vales e cabeceiras de vale (Oliveira et al. 2001).

MÉTODOS Este trabalho apresenta resultados obtidos de duas seqüências pedoestratigráficas. Características como cor, espessura, geometria, textura, estrutura e teor de cascalho fo- ram descritas e amostras foram coletadas para análises variadas. Análises granulométricas foram realizadas no Laboratório de Pedologia do Departamento de Geociências da U.F.S.C., segundo procedimento padrão (Lima 2005). Os resultados texturais foram inseridos em diagramas triangulares, segundo a classificação para sedimentos lamosos de Flemming (2000). Amostras com teores importantes de cascalho foram classificadas segundo Folk (1974). Em alguns casos, optou-se pela representação dos resultados texturais sob a forma de índice granulométrico $\left(\%_{<2 \mu \mathrm{m}}\right.$ .$\left.\%_{>10 u m}^{-1}\right)$, que expressa em percentuais relativos a razão entre grãos menores do que 2 micra e grãos maiores do que 10 micra (Wilson et al. 2000). Amostras de unidades sedimentares cujas partículas são compostas principalmente por alterorrelíquias (Delvigne 1998), friáveis e inadequadas ao tratamento mecânico, foram impregnadas com resina de poliéster, fatiadas e reduzidas a lâminas delgadas para análise por microscopia óptica (Scholle 1979, Fitzpatrick 1984, Bullock 1985). Essas análises foram efetuadas nos Laboratórios de Petrografia e de Laminação do Departamento de Geociências da UFSC. Imagens digitais de lâminas delgadas foram obtidas através de scanner de slides CanoScan-2710, de modo a efetuar análise em escala intermediária entre a microscópica e a macroscópica (De Keyser, 1999).

Testemunho de unidade turfosa em uma das seções estudadas foi submetido à análise palinológica. Amostras coletadas a intervalos de 5 centímetros foram processadas de acordo com método padrão de análise polínica. A soma total de polens inclui grãos de gramíneas, arbustos e árvores. Esporos de liquens e de fungos foram contados em lâminas polínicas e expressos em percentagem da soma total de polens. A representação gráfica dos dados polínicos, o cálculo e a análise de agrupamento (cluster) foram realizados com o uso dos programas TILIA, TILIAGRAPH e CONISS (Grimm 1987). Os polens analisados foram agrupados em Campos, Floresta de Araucária e Floresta Tropical Atlântica. A análise foi efetuada no Departamento de Geociências da Universidade de Bremen, Alemanha.

$\mathrm{O}$ carbono do solo (carbono orgânico total e $\delta{ }^{13} \mathrm{C}$ ) foi analisado no Laboratório de Isótopos Estáveis do Centro de Energia

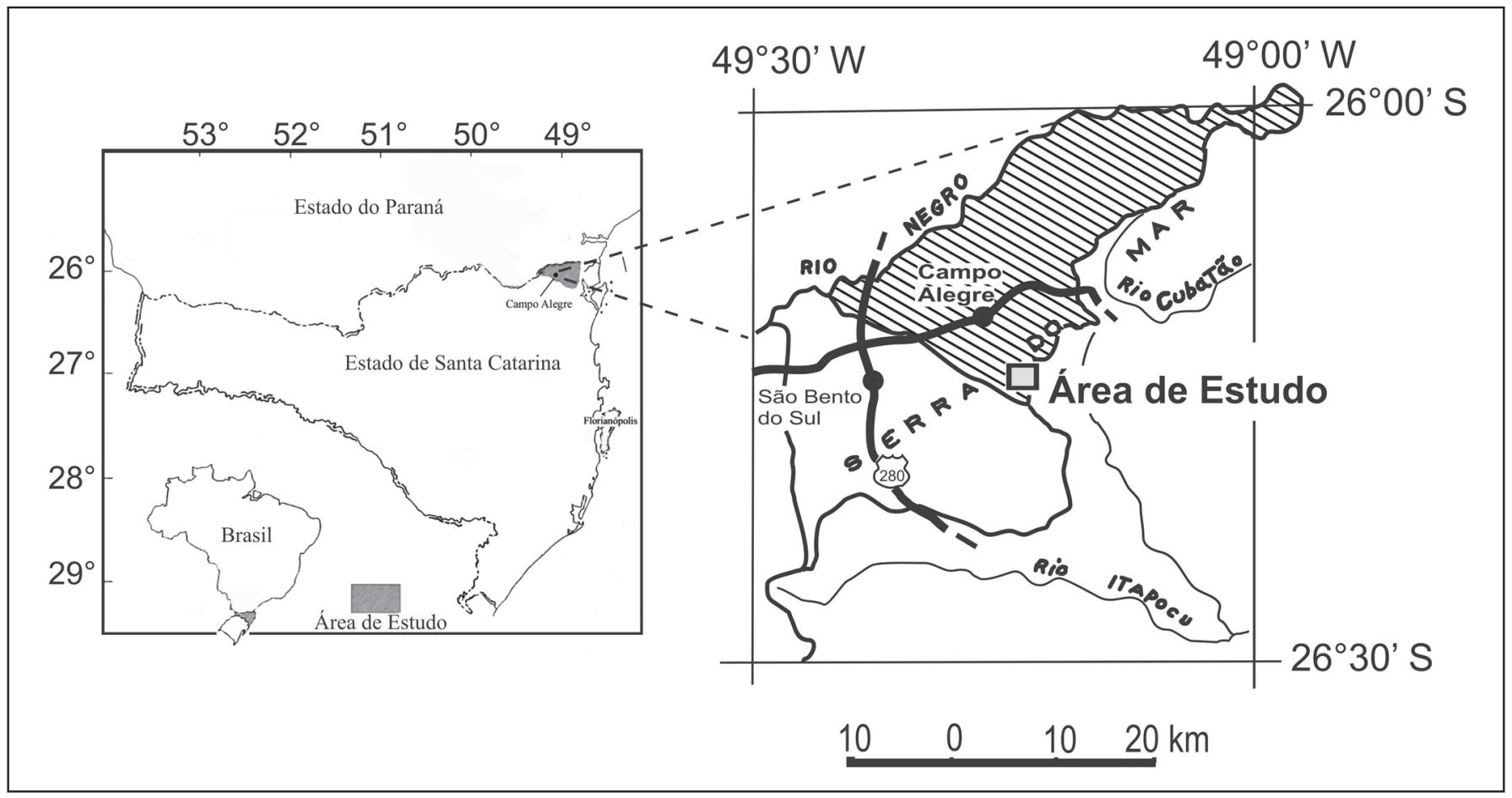

Figura 1 - Localização da área de estudo. 
Nuclear na Agricultura (CENA, Piracicaba), sendo o $\delta{ }^{13} \mathrm{C}$ relativo à razão ${ }^{13} \mathrm{C} /{ }^{12} \mathrm{C}$ do padrão internacional PeeDee Belemnite - PDB (Belemnitella americana da formação cretácea PeeDee, Carolina do Sul, EUA), expresso pela notação convencional $(\%)$ :

$$
\delta^{13} \mathrm{C}(\%)=\left[\left(\mathrm{R}_{\text {amostra }} / \mathrm{R}_{\text {padrão }}\right)-1\right] .1 .000,
$$

onde: $\mathrm{R}_{\text {amostra }}$ e $\mathrm{R}_{\text {padrão }}$ correspondem, respectivamente, ao quociente ${ }^{13} \mathrm{C} /{ }^{12} \mathrm{C}$ da amostra e do padrão.

Datações ${ }^{14} \mathrm{C}$ foram efetuadas no Laboratório ${ }^{14} \mathrm{C}$ (CENA, Piracicaba), no Instituto de Física da Universidade ErlangenNürnberg (Alemanha), e na Beta Analytic Inc. (E.U.A.). Datações por termoluminescência (TL) e por luminescência oticamente estimulada (LOE) foram realizadas no Laboratório de Vidros e Datações (FATECSP).

\section{SEQÜENCIAS PEDOESTRATIGRÁFICAS E REGIS-} TRO QUATERNÁRIO Duas seções pedoestratigráficas são estudadas, situadas em locais distintos, com cerca de 900 metros de distância entre ambos. A primeira seção ocupa posição de alta encosta, próxima aos divisores de água, representando seqüência de fluxos gravitacionais adjacentes a uma cabeceira de vale. A segunda seção se situa em posição típica de cabeceira de vale, na baixa encosta, onde zonas de saturação tendem a concentrar-se em depressões topográficas que alimentam canais de primeira ordem. Figura esquemática (fig. 2) ilustra o posicionamento dessas duas seções em cabeceira de vale idealizada.

1 - SEQÜENCIA PEDOESTRATIGRÁFICA EM ALTA ENCOS$T A$ ( $A$, na figura 2) Representação esquemática da seqüência pedoestratigráfica preservada nas proximidades de divisor de águas é ilustrada pela figura 3 .

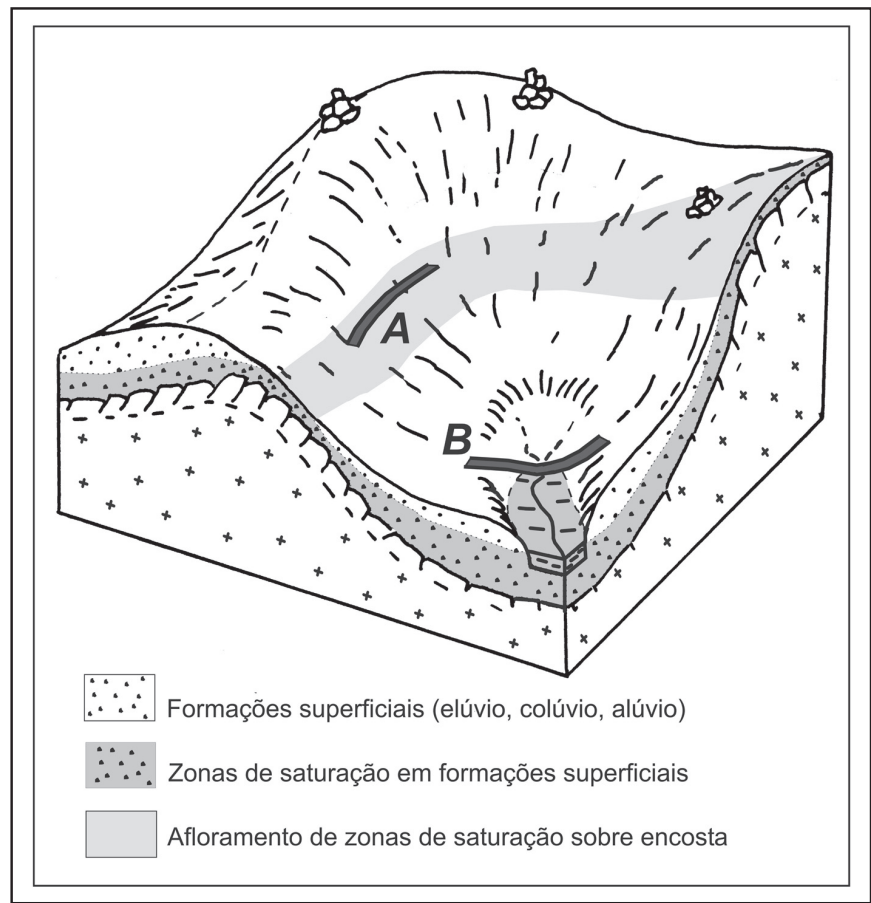

Figura 2 - Representação esquemática de cabeceira de vale. A posição topográfica da seção de alta encosta e a da de cabeceira são indicadas, respectivamente, pelas bandas " $A$ " $e$ " $B$ ". Adaptado de Cosandey \& Oliveira (1996). Notar distribuição de zonas de saturação da água do solo.
Na base da seqüência ocorrem camadas coluviais lenticulares cobertas por horizonte superficial húmico enterrado, relativamente espesso (Unidade 5). Sobreposto a essa unidade, intercalado com camadas finas subparalelas de colúvio, outro horizonte superficial enterrado pode ser notado (Unidade 11). A seqüência apresenta, no centro da figura, truncamento por feições acanaladas, constituindo estruturas de corte e preenchimento. Essas estruturas foram preenchidas por material coluvial não-diferenciado, formando camada espessa cuja geometria acompanha a topografia atual. A seqüência termina, no topo, com espesso horizonte húmico característico dos solos desse planalto meridional. A classificação textural dos materiais da seqüência pode ser observada na figura 4.

Como previsto por Flemming (2000), materiais de fácies distintas tendem a se agrupar em diferentes zonas do diagrama. Amostras das unidades coluviais se agrupam em torno do centro do diagrama, enquanto amostras das unidades pedogenéticas (unidades 5 e 11) estão distribuídas em espectro mais largo de classes texturais, mais ricas em silte. $\mathrm{O}$ teor de cascalho das amostras coluviais varia de $4,3 \%$ a $12,4 \%$, caindo para $0,4 \%$ nas amostras dos horizontes pedogenéticos enterrados (Oliveira \& Lima 2004). Datações pelo método do ${ }^{14} \mathrm{C}$ obtidas para

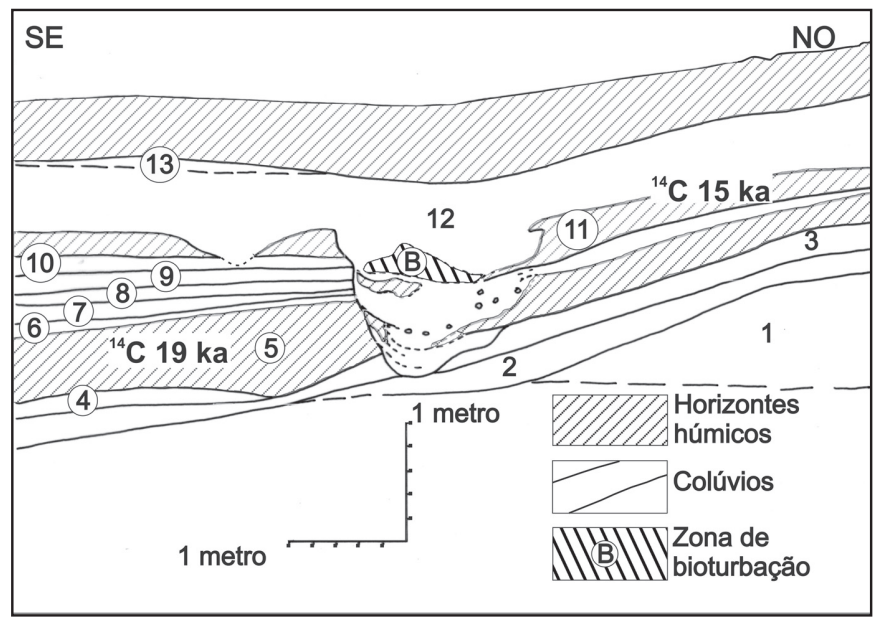

Figura 3 - Representação esquemática de seção pedoestratigráfica em alta encosta

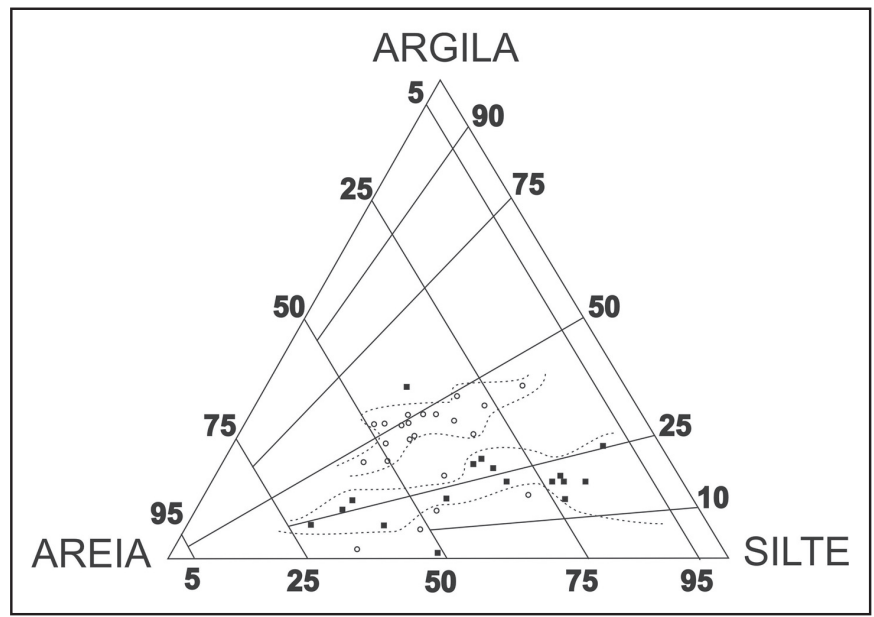

Figura 4 - Diagrama de classificação textural de Flemming (2000) para as amostras da seção pedoestratigráfica de alta encosta. Quadrados fechados: solos. Círculos abertos: colúvios. 
Tabela 1 - Idades ${ }^{14} \mathrm{C}$ dos horizontes enterrados na seção de alta encosta

\begin{tabular}{ccccccc|}
\hline $\begin{array}{c}\text { Código } \\
\text { Laboratório } \\
(\#)\end{array}$ & $\begin{array}{c}\text { Código de } \\
\text { Campo } \\
(\#)\end{array}$ & $\begin{array}{c}\text { Profundidade } \\
\text { da Amostra } \\
(\mathrm{m})\end{array}$ & $\begin{array}{c}\text { Unidade } \\
\text { Estratigráfica }\end{array}$ & $\begin{array}{c}\text { Tipo de } \\
\text { Análise }\end{array}$ & $\begin{array}{c}\text { Idade } \\
\left(\text { anos }{ }^{14} \mathrm{C} \text { AP }\right)\end{array}$ & $\delta{ }^{13} \mathrm{C}(1)$ \\
\hline Beta- 124761 & CA.24-10.A1 & 1,2 & 11 & AMS & $15,260 \pm 80$ & -25.0 \\
& & 2,2 & 5 & AMS & $19,130 \pm 110$ & -25.0 \\
\hline Beta-106474 & CA.S-1 & & & & & \\
\hline
\end{tabular}

amostras das unidades 5 e 11 estão relacionadas na Tabela 1. De acordo com as idades estimadas, a unidade 5 se desenvolveu durante o Último Máximo Glacial (UMG), e a unidade 11, entre o UMG e o Holoceno.

As unidades pedogenéticas apresentam cor preta (10YR 2/1), e a análise do teor total de carbono permite classificá-las como horizontes superficiais húmicos (Lima 2005). Os teores de matéria orgânica e valores de $\delta^{13} \mathrm{C}$ obtidos para os horizontes enterrados de tal seqüência constam da figura 5, na qual os valores de $\delta^{13} \mathrm{C}$ indicam mistura de plantas do tipo $\mathrm{C}_{3}$ (árvores) e do tipo $\mathrm{C}_{4}$ (gramíneas) em ambos os horizontes superficiais enterrados.

Os resultados de matéria orgânica nos solos (MOS) indicam a presença de gramíneas, acompanhadas provavelmente de árvores típicas de cerrado/campo, sugerindo que os setores mais elevados do relevo local também foram ocupados por árvores e arbustos durante o UMG. Os sinais do $\delta^{13} \mathrm{C}$ entre $-22 \mathrm{e}-19$ por mil sugerem variação provável de vegetação de cerrado/campo nos horizontes enterrados, indicando, respectivamente, a incorporação de matéria orgânica a partir de campos mais sujos (valores mais negativos) e de campos mais limpos (valores menos negativos). Essa ocupação mista sugere que o reconhecido predomínio de vegetação campestre nos setores mais elevados do relevo em áreas tropicais durante os períodos mais frios do Pleistoceno tardio deve ser considerado com cautela, priorizando considerações evolutivas locais (Thomas et al. 2001).

\section{2 - SEQÜENNCIA PEDOESTRATIGRÁFICA EM CABECEIRA} $D E \operatorname{VALE}(B$, na figura 2) Essa seqüência foi investigada em parede exposta no interior de mina de argila. A seção representa ambiente típico de cabeceira de vale, no qual episódios de erosão e sedimentação se intercalam com períodos de desenvolvimento de solos alagados. Representação esquemática da seqüência pedoestratigráfica é ilustrada pela figura 6. Detalhes sobre as datações ${ }^{14} \mathrm{C}$, LOE e TL, obtidas para a seqüência, podem ser observados nas Tabelas 2 e 3. Em função das datações obtidas, essa seqüência pedoestratigráfica pode ser subdividida em duas seqüências distintas, uma pleistocênica (unidades 1, 2, 3 e 4) e outra holocênica (unidades 5, 6, 7 e 8).

A seqüência pleistocênica inicia com camada alúvio-coluvial de 30 a $50 \mathrm{~cm}$ de espessura, formada por lentes subparalelas de cascalho alterado (grânulos e seixos), desenvolvendo localmente laminação cruzada (Unidade 1). Essa unidade repousa sobre discordância erosiva escavada sobre alteritas das rochas piroclásticas locais e data, provavelmente, do início do último estágio glacial. A passagem para a unidade sobrejacente é abrupta e ocorre através de lâminas lamosas que se tornam cada vez mais escuras até formar depósito carbonoso de aproximadamente $150 \mathrm{~cm}$ de espessura (Unidade 2). As idades obtidas para a unidade 2 sugerem que o topo do depósito se desenvolveu durante o estágio isotópico marinho 3 (EIM 3), enquanto a base se situa, provavelmente, além do alcance da datação C-14 realizada. Esta unidade (Unidade 2) está coberta por aproximada-

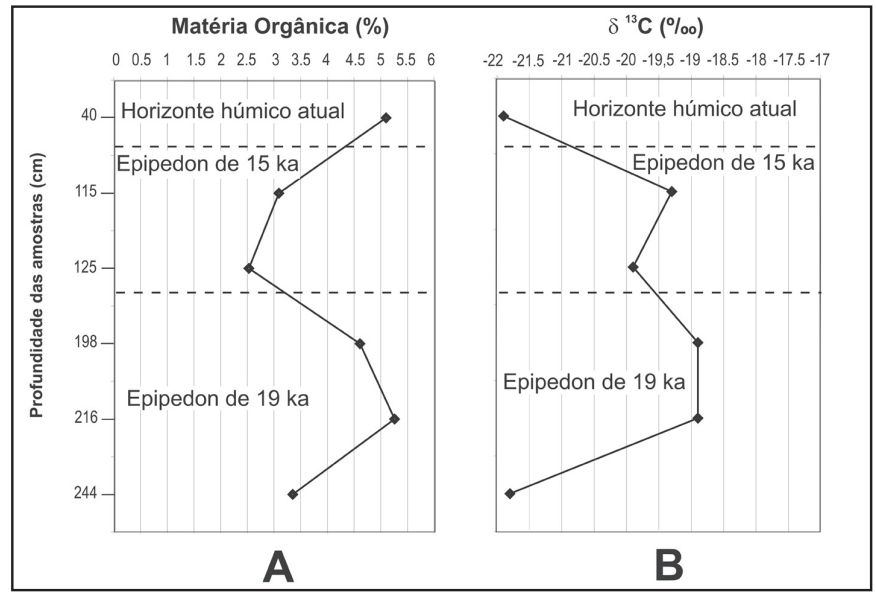

Figura 5 - Teores de carbono no solo (A) e valores do índice $\delta^{13} C(B)$ para os horizontes pedogenéticos enterrados. Valores de $\delta^{13} C$ entre -30 e -22 implicam plantas $C_{3}$ (árvores); valores entre -17 e -9 implicam plantas do tipo $C_{4}$ (gramíneas).

mente 1,5 metro de colúvio não-diferenciado, fortemente alterado por hidromorfia (Unidade 3). A unidade 3 preservou, em seu topo, remanescentes de um paleoorizonte A enterrado, truncado pela erosão (Unidade 4) (Fig. 6). Um depósito residual de areias grossas bem selecionadas foi encontrado ao longo da discordância erosiva do topo da unidade 4. Esse depósito de areia, datado de aproximadamente 6.600 anos A.P. por (LOE), marca na seção o limite entre uma seqüência de sedimentos pleistocênicos e uma de sedimentos holocênicos.

Foi efetuada análise textural detalhada de amostras das unidades 2, 3, 4 e 6, de ambas as seqüências. O depósito carbonoso da unidade 2 foi submetido à análise sedimentológica detalhada; à análise polínica, e à análise isotópica. A classificação textural dos materiais da unidade 2 é apresentada na figura 7.

No conjunto, as amostras desta unidade podem ser agrupadas de acordo com duas zonas distintas: uma inferior, mais grossa, e outra superior, mais fina, tal como ilustra o diagrama da figura 8. Duas zonas texturais se destacam: uma abaixo de $590 \mathrm{~cm}$ de profundidade e outra acima deste nível. Nota-se forte enriquecimento de argila entre as duas zonas.

$\mathrm{O}$ diagrama sumário do percentual de polens obtido para essa unidade (Unidade 2), incluindo a concentração de polens e o dendrograma de agrupamento, é ilustrado pela figura 9. Baseado no dendrograma, o diagrama polínico também permite a divisão do depósito carbonoso em duas zonas distintas: respectivamente zona polínica I e zona polínica II. A figura 10 ilustra o diagrama de distribuição percentual de polens do depósito, no qual as famílias e gêneros mais significativos são agrupados de acordo com a soma total de polens, indicando sua origem de vegetação campestre e de florestas de Araucária, Atlântica etc. 


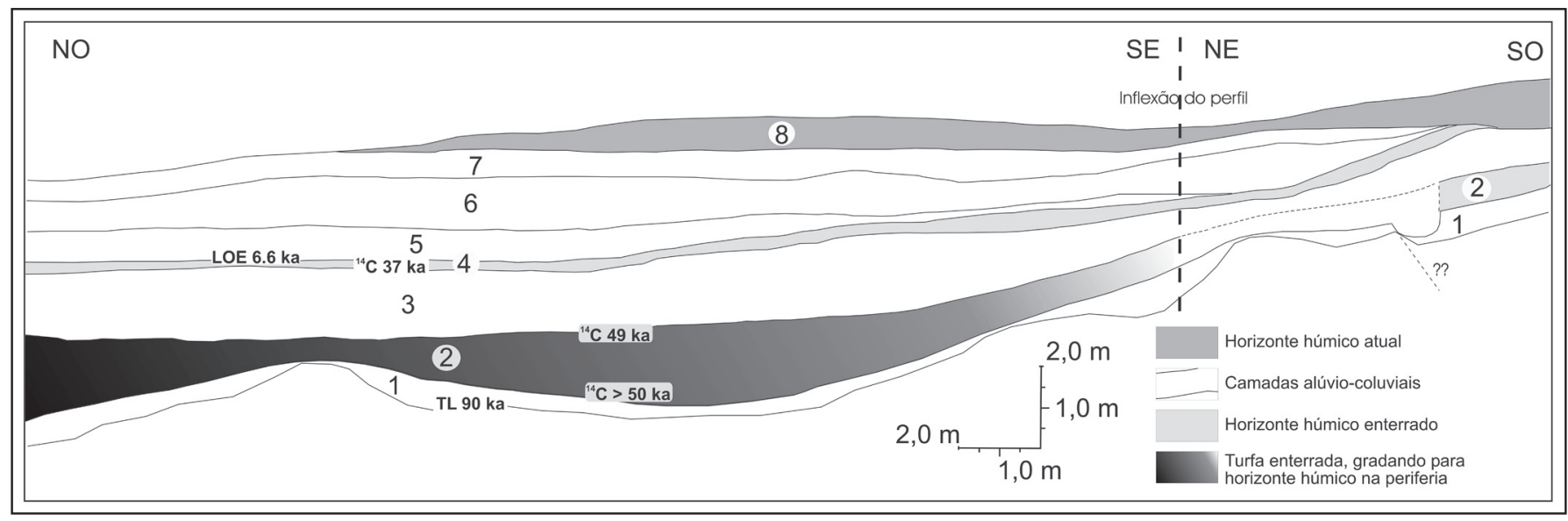

Figura 6 - Seqüência pedoestratigráfica esquemática em cabeceira de vale. Principais unidades enumeradas: 1 - alúvio-colúvio, com lentes subparalelas de cascalho; 2 - turfa pleistocênica; 3 -colúvio hidromorfizado; 4 - paleo-horizonte A; 5 - cascalho lamoso, com clastos intemperizados; 6-alúvio-colúvio finamente estratificado; 7: alúvio-colúvio cascalho lamoso; 8: horizonte húmico atual. Notar, no setor NE-SO da seção, alteração das unidades 1 e 2 na proximidade de plano de falha.

Idades ${ }^{14} \mathrm{C}$ do topo e da base da Unidade 2, assim como da Unidade 4, na seqüência de cabeceira de vale.

\begin{tabular}{|ccccccc|}
\hline $\begin{array}{c}\text { Código Laboratório } \\
(\#)\end{array}$ & $\begin{array}{c}\text { Código de } \\
\text { Campo } \\
(\#)\end{array}$ & $\begin{array}{c}\text { Profundidade } \\
\text { da Amostra } \\
(\mathrm{m})\end{array}$ & $\begin{array}{c}\text { Unidade } \\
\text { Estratigráfica }\end{array}$ & $\begin{array}{c}\text { Tipo de } \\
\text { Análise }\end{array}$ & $\begin{array}{c}\text { Idade } \\
\left(\text { anos }{ }^{14} \mathrm{C} \text { AP }\right)\end{array}$ & $\delta^{13} \mathrm{C}(1)$ \\
\hline \#953 / CENA \# 520 & Paleo-2 & 2,5 & 4 & AMS & $37.000 \pm 1.425$ & -19.5 \\
$\# 851$ / CENA \# 444 & CA-TOPO & 5.4 & 2 (topo) & Convencional & $49,300+9,700$ & -29.0 \\
& & & & & $-4,250$ & \\
Erl- 5456 & PH-09/02-2 & 6.9 & 2 (base) & AMS & $>50,000$ & -28.82 \\
\hline
\end{tabular}

Tabela 3 - Dose anual, dose acumulada (P) e idades medidas em amostras arenosas da seqüencia de cabeceira de vale.

\begin{tabular}{|cccccccc|}
\hline $\begin{array}{c}\text { Código do } \\
\text { Laboratório } \\
(\#)\end{array}$ & $\begin{array}{c}\text { Código de } \\
\text { Campo } \\
(\#)\end{array}$ & $\begin{array}{c}\text { Profundidade } \\
(\mathrm{m})\end{array}$ & $\begin{array}{c}\text { Unidade } \\
\text { estratigráfica }\end{array}$ & Método & $\begin{array}{c}\text { Dose anual } \\
(\mu \mathrm{Gy} / \text { ano })\end{array}$ & $\begin{array}{c}\text { P } \\
(\mathrm{Gy})\end{array}$ & $\begin{array}{c}\text { Idade } \\
(\text { anos })\end{array}$ \\
\hline LVD- 662 & CA-SC-73 & 3.4 & 5 (base) & LOE & $436 \pm 40$ & 2.89 & $6,625 \pm 750$ \\
LVD- 1127 & CA-base-LOE & 7.5 & 1 (base) & TL & $1,800 \pm 40$ & 150 & $90,000 \pm 11,000$ \\
\hline
\end{tabular}

A zona polínica I ( 150 - $45 \mathrm{~cm}$ abaixo do topo da camada) é caracterizada por alta concentração de polens de vegetação campestre (60 - 67\%), principalmente por Poaceae, seguida de Cyperaceae, Baccharis, Asteraceae subf. Asterioideae, além de Apiaceae, Eryngium e Valeriana, que ocorrem em percentuais inferiores. O somatório de polens de Floresta de Araucária é inferior (25-32\%), representado principalmente por Myrtaceae, seguida de Podocarpus, Weinmannia, Melastomataceae, Myrsine, Ilex, Symplocos e Daphnopsis. Grãos de pólen de Araucaria angustifolia estão ausentes das amostras, com exceção de um único grão. Percentuais de polens relacionados com a Floresta Atlântica são baixos (1 - 3\%) e representados apenas por grãos unitários de Alchornea, Celtis e Moraceae/Urticaceae. Polens de plantas aquáticas não ocorrem nas amostras, ou foram localizados apenas como grãos individuais. Esporos de samambaias arbóreas, como Cyathea e Dicksonia, ocorrem em baixos percentuais. São mais freqüentes esporos de samambaias do tipo Blechnum imperiale e monlete psilate. Liquens são raros.

A zona polínica II $(45-0 \mathrm{~cm}$ abaixo do topo da camada) apresenta polens de vegetação campestre, que predomina ao longo da seqüência $(60$ - 70\%). Percentuais de Eryngium são relativamente baixos, enquanto as demais famílias de plantas campestres permanecem inalteradas. A soma de polens de Floresta de Araucária é similar à da zona I. Porém, verifica-se mu- 


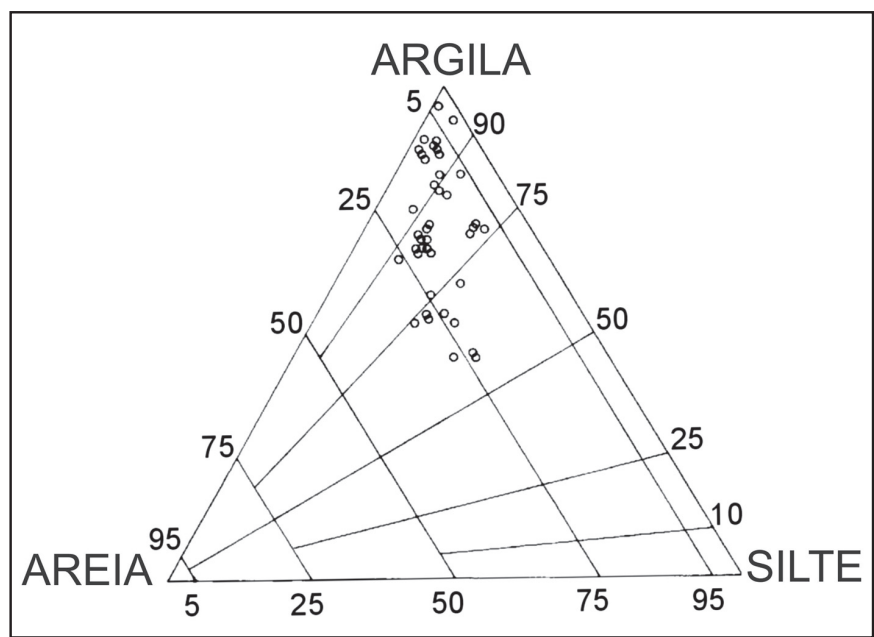

Figura 7 - Diagrama de classificação textural para as amostras da unidade 2

\section{Índice Granulométrico $(<2 \mu \mathrm{m} />10 \mu \mathrm{m} .100)$}

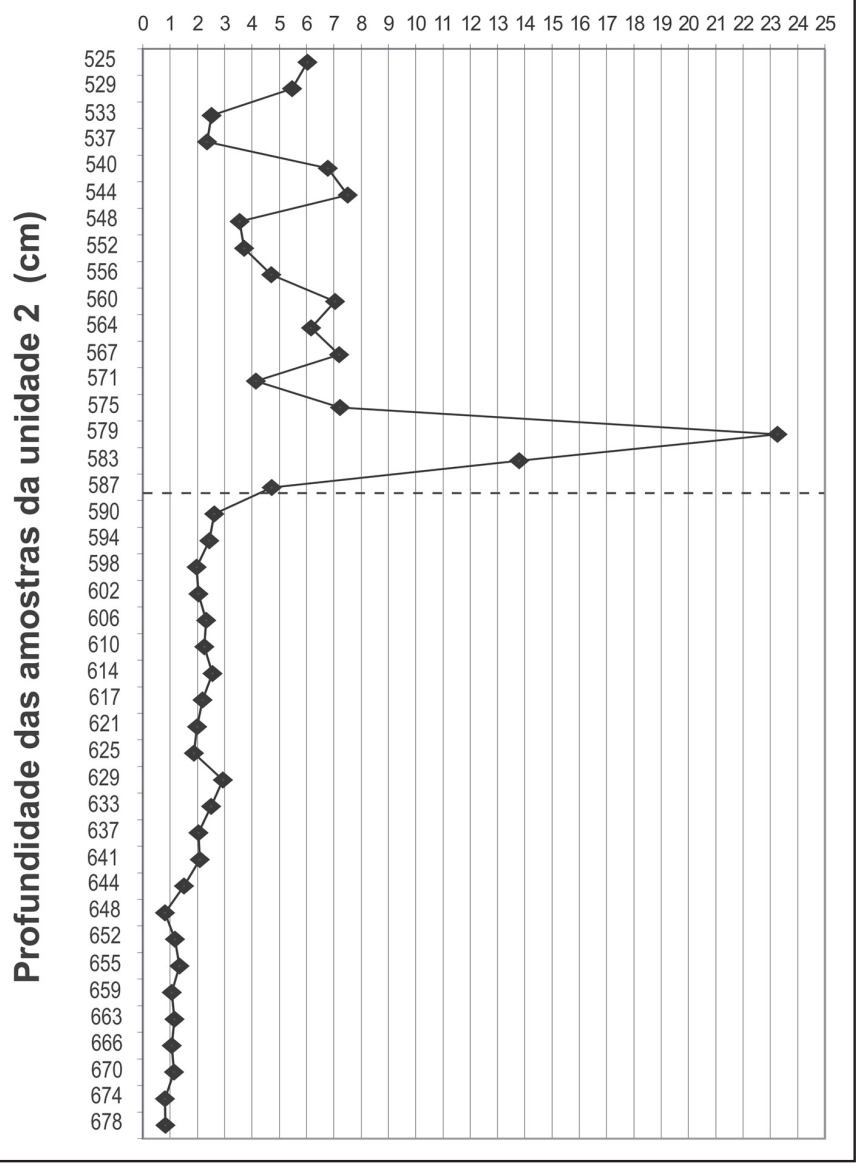

Figura 8 - Variação relativa dos teores de lama (silte e argila) e de areia ao longo da unidade 2

dança na composição desse grupo, segundo a qual a ocorrência de Myrtaceae é relativamente menor do que na zona I, enquanto o percentual de Podocarpus é marcadamente superior. Paralelamente, os percentuais de Weinmannia são reduzidos nesse nível. Percentuais do grupo da Floresta Atlântica permanecem em níveis baixos $(1-2 \%)$; porém, a ocorrência de polens de
Melastomataceae/Combretaceae diminui, enquanto aumenta a ocorrência de Myrsine. A ocorrência de esporos de samambaias arbóreas e de Blechnum imperiale é igualmente reduzida na zona II.

Os resultados polínicos sugerem mudança paleoambiental a partir de período de clima relativamente mais seco e mais quente, na zona polínica I, para período de clima mais frio e mais úmido, na zona polínica II (Fig. 9 e Fig. 10). Essa inferência é sustentada pela maior representação de Podocarpus e pela ocorrência rara de Weinmannia na zona polínica II, mais jovem. De fato, Podocarpus necessita de ambientes relativamente úmidos para se desenvolver, enquanto Weinmannia é muito sensível a baixas temperaturas (Behling et al. 2004).

A análise do $\delta^{13} \mathrm{C}$ do solo da unidade 2 sugere o predomínio de espécies arbóreas e, provavelmente, de gramíneas $\mathrm{C}_{3}$, como Cyperaceae, ao longo de toda a unidade (Fig. 11). Os teores totais de carbono do solo diminuem gradualmente, da base para o topo do perfil. A associação entre gramíneas $\mathrm{C}_{3} \mathrm{e}$ árvores, na unidade 2, durante período correlacionável ao EIM 3, pode ser explicada tanto em função do caráter interestadial desse estágio isotópico, quanto em função da topografia local, característica de cabeceiras de vale, configurando domínio de transição entre a vegetação de campos dos interflúvios e as matas-galeria dos vales.

Sobrepostas a essa unidade carbonosa, as unidades 3 e 4 são compostas principalmente por material que é classificado texturalmente como lama arenosa levemente argilosa. Apenas uma das 10 amostras analisadas nessas unidades foi classificada como lama arenosa levemente siltosa. Essas unidades constituem, respectivamente, sedimento não diferenciado hidromorfizado e horizonte A moderado truncado, desenvolvido diretamente sobre o horizonte $\mathrm{C}$ coluvial.

A figura 11 traz ainda, no topo do diagrama, resultados obtidos no horizonte truncado da unidade 4. Esse horizonte A moderado (Unidade 4) apresenta valores de $\delta^{13} \mathrm{C}$ que indicariam relativa abertura da vegetação, com presença de gramíneas $\mathrm{C}_{4}$, provavelmente associadas a clima mais seco do que o clima que predominou durante a formação da unidade 2. Esses resultados indicam, globalmente, clima mais úmido na parte do perfil relacionada às amostras da unidade 2 , e clima mais seco na parte relacionada à unidade 4 (Fig. 11). Esse resultado é relativamente coerente com os obtidos através dos diagramas polínicos das figuras 9 e 10, implicando o predomínio de condições locais relativamente úmidas durante o período de formação da unidade 2.

A seqüência pleistocênica do depósito estudado é caracterizada, portanto, pela alternância de períodos de erosão e sedimentação e períodos de pedogênese em ambiente no qual o lençol freático teria permanecido em nível relativamente elevado, condicionando o desenvolvimento de condições propícias ao hidromorfismo. Essas condições paleoidrológicas, marcadas por pedoclima saturado em água, teriam prevalecido durante o desenvolvimento da seqüência, em período correlacionado ao interestádio do EIM 3 (Unidade 2), ao final do qual condições de maior déficit hídrico teriam prevalecido, com formação de horizonte A moderado (Unidade 4).

A seqüência holocênica inicia com o truncamento da unidade 4. Datação de areias preservadas ao longo da descontinuidade erosiva sugere que o truncamento da unidade 4 ocorreu no Holoceno Médio. Essa seqüência holocênica, portanto, inicia com $75 \mathrm{~cm}$ de cascalho lamoso organizado em gradação normal (Unidade 5). Seguem aproximadamente 2,5 metros de alúviocolúvio finamente estratificado, composto por lentes alternadas de alterorrelíqueas de cascalho, areia e lama (Unidades 6 e 7) (ver Fig. 6).

Devido ao grau avançado de alteração dos clastos que compõem essas unidades, a análise da textura e de estruturas sedi- 


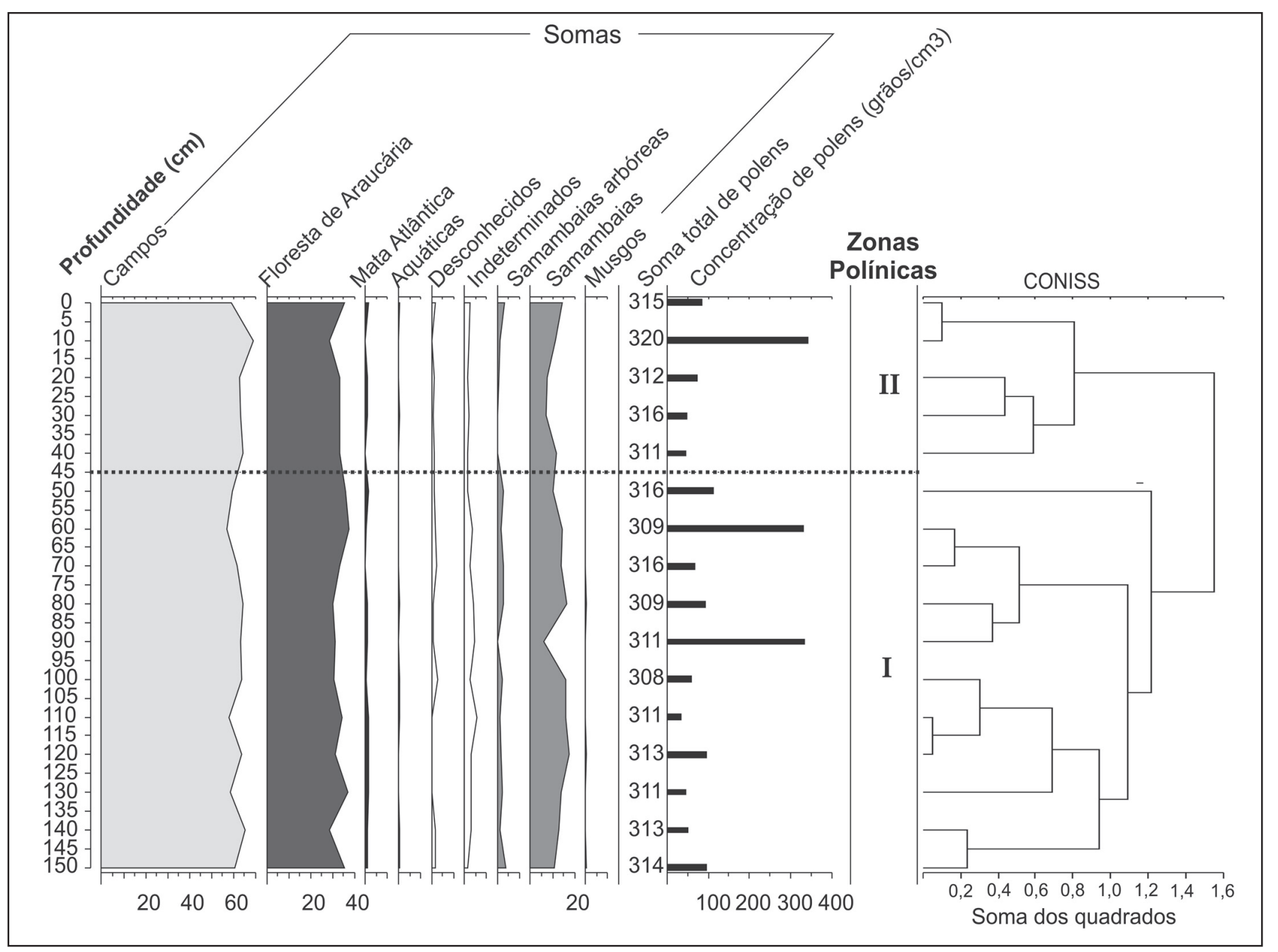

Figura 9 - Diagrama sumário do percentual de polens da unidade carbonosa. Profundidades a partir do topo da camada.

mentares de detalhe foi efetuada através de lâminas delgadas. As lâminas foram obtidas de amostras coletadas ao longo da descontinuidade erosiva, abarcando parcialmente a unidade $4 \mathrm{e}$ a unidade 5, e ao longo das lentes coluviais da unidade 6 . A figura 12 ilustra feições de detalhe na transição entre o solo erodido da unidade 4 e a unidade 5 , sobrejacente.

A descrição de feições micromorfológicas nessa transição sugere, principalmente, os seguintes processos: a) tração prédeposicional sobre o horizonte A truncado; b) preenchimento de fendas por pedorrelíquias; c) acumulação de material carbonizado no interior de pedotúbulos (Sant'Ana et al. 2005). A descrição micromorfológica de amostras das unidades 5 e 6 indica importante desenvolvimento de cutãs iluviais, sobretudo nas unidades lamosas do depósito (Oliveira \& Ferreira 2004). No conjunto, essas análises indicam: a) dessecamento do antigo horizonte superficial (Unidade 4); b) enterramento relativamente rápido, subseqüente ao processo erosivo; c) ocorrência de incêndios, carbonizando raízes; d) transformação pós-deposicional do alúvio-colúvio sobrejacente (Unidade 5).

A unidade 6 é composta por material no qual ocorre alternância de lentes de lama e de cascalho. Caso fossem inseridas em diagramas triangulares para classificação textural, as amostras das lentes lamosas seriam classificadas como lama arenosa argilosa $(\mathrm{C}-\mathrm{V})$ e lama levemente arenosa muito argilosa $(\mathrm{D}-\mathrm{V})$, segundo Flemming (2000), enquanto as subunidades cascalhosas seriam classificadas como lama cascalhosa, cascalho lamoso e areia lamosa cascalhosa, segundo o diagrama ternário de
Folk (1974). A figura 13 ilustra lâminas delgadas digitalizadas de amostra da unidade 6 (Fig. 13.a) e de amostra de depósito de chuva atual (Fig. 13.b), criado por escoamento superficial durante evento chuvoso na área de estudo.

O depósito atual foi produzido após três dias de precipitação, entre os dias 12 e 15 de março de 2002, com total médio acumulado de $59,7 \mathrm{~mm}$ e intensidade da chuva, ao longo de 6 horas, entre 1,9 e $6,8 \mathrm{~mm} \cdot \mathrm{h}^{-1}$ (dados do Centro de Meteorologia e Informação Tecnológica - Epagri/Ciram/Climerh, 2004). Ele foi observado no piso da mina estudada e o seu material tem como fonte o mesmo substrato alterado que serviu à formação da seqüência holocênica (Fig. 14).

Tal como ilustrado na figura 13.a, a amostra holocênica é composta, principalmente, por lâminas discretas e compactadas de cascalho e de lama maciça. Já a amostra do depósito atual (Fig. 13.b) possui maior organização preferencial, como gradação normal e laminação cruzada, com grãos dispostos em empacotamento mais aberto (Oliveira \& Ferreira 2004). A alternância entre unidades finas e grossas é comum em ambas amostras (Fig. 13). As similaridades entre as duas amostras são interpretadas como indícios de que a amostra holocênica também teria sido formada sob a influência do escoamento superficial difuso. A alternância entre unidades finas e grossas é atribuída a variações do escoamento superficial no momento da formação de ambos os depósitos.

A seqüência holocênica revela, portanto, depósitos formados sob a influência do escoamento superficial difuso, nas en- 


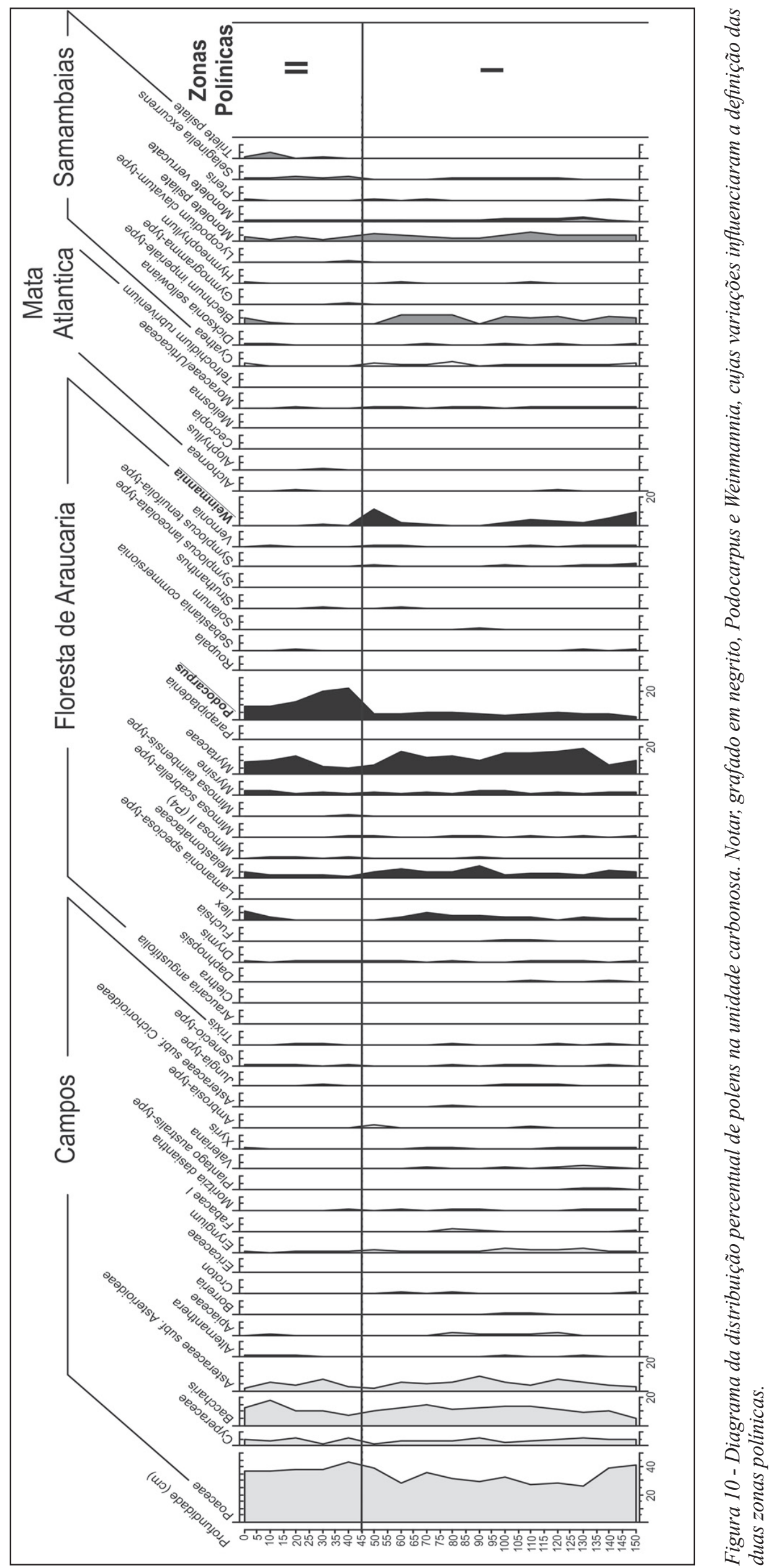




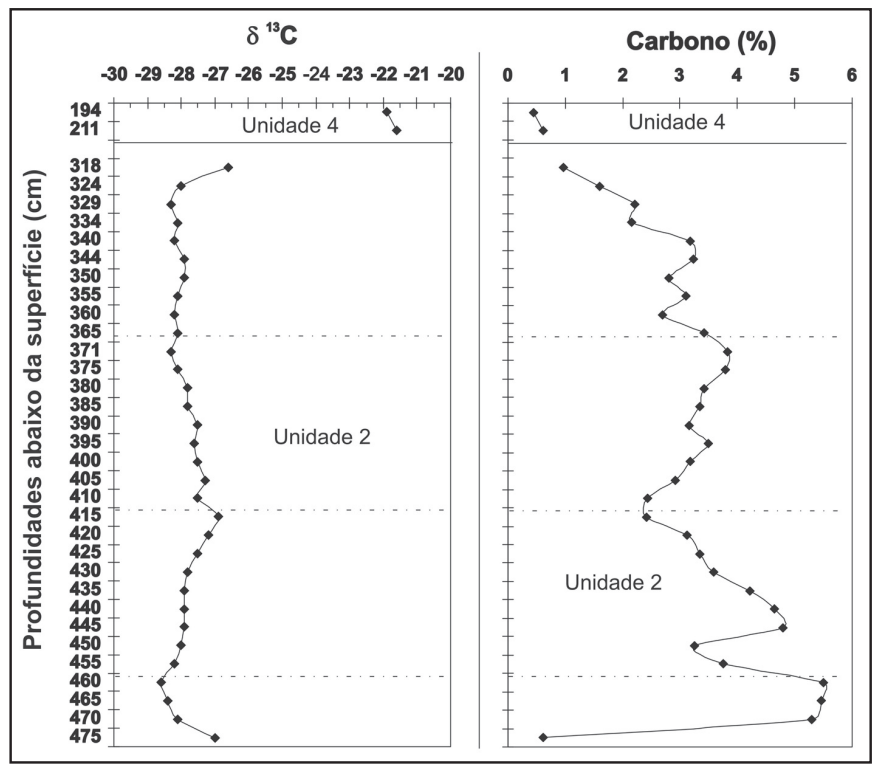

Figura 11 - Valores do índice $\delta^{13} \mathrm{C}$ e teores de carbono ao longo da unidade 2 e em amostras da unidade 4 . Valores de $\delta^{13} \mathrm{C}$ entre -30 e -22 implicam plantas $\mathrm{C}_{3}$ (árvores); valores entre -17 e -9 implicam plantas do tipo $\mathrm{C}_{4}$ (gramíneas).

costas adjacentes à cabeceira de vale estudada. Globalmente, os depósitos dessa seqüência sugerem período de agradação local, provavelmente relacionado a ambiente do Holoceno Médio no qual estações contrastadas poderiam causar rarefação da vegetação, dessecamento do solo, incêndios, escoamento superficial, erosão e deposição sobre encostas desprovidas de cobertura vegetal densa (ver Fig. 14).

EVIDÊNCIAS DE MUDANÇAS AMBIENTAIS PLEISTOCÊNICAS E HOLOCÊNICAS EM CABECEIRAS DE

VALE As duas seqüências pedoestratigráficas estudadas revelam padrão deposicional variado, em cabeceiras de vale, e se complementam cronologicamente, abarcando intervalo de tempo entre o início do último estágio glacial e o Holoceno Médio. Síntese das duas seqüências pedoestratigráficas e das principais características das unidades investigadas é apresentada através de seção colunar, representando a espessura máxima das unidades (Fig. 15). Saliente-se, entretanto, que a figura 15 representa seqüências pedoestratigráficas espacialmente distintas, empilhadas na figura em função das datações obtidas, o que permite a subdivisão dos depósitos do estudo em três 3 seqüências cronologicamente distintas: a) Seqüência Inferior; b) Seqüência Intermediária; c) Seqüência Superior.

As idades para os depósitos das seqüências do estudo são coerentes com outras datações obtidas nos três estados do Sul do Brasil. Tal como sugerido pela figura 16, essas datações apontam para sinal relativamente consistente que abarca idades correlacionáveis aos estágios isotópicos marinhos 1, 2 e 3, com provável extensão para o estágio 5 . Com base nos resultados apresentados, algumas conjecturas sobre mudanças ambientais quaternárias na área do estudo são propostas a seguir.

1 - SEQÜENCIA INFERIOR: PEDOGENNESE, MORFOGE NESE E ELEVAÇÃO DO LENÇOL FREÁTICO EM CABECEIRAS DE VALE DURANTE O ÚLTIMO ESTÁDIO GLACIAL (EIM 3 a EIM 5b?) A interpretação do registro contido nos depósitos mais antigos da seqüência inferior (Fig. 15) é resumida a seguir.

a) Deposição de camada de alúvio-colúvio em desconfor- midade erosiva sobre o manto de intemperismo local, em torno de $90 \mathrm{ka} \mathrm{A.} \mathrm{P.} \mathrm{(Unidade} 1$ da figura 15). Essa camada se enriquece gradualmente em material orgânico, marcando o início de horizonte turfoso associado ao desenvolvimento de ambiente alagado na cabeceira de vale.

b) Durante período correlacionável ao interestádio do EIM 3 , verifica-se clima local mais frio e mais seco do que o clima atual. Apesar disto, banhados e alagados ainda se desenvolvem no local (Unidade 2, figura 15), formando horizonte turfoso que traz em seu registro polínico evidências de clima relativamente mais quente e seco no início do depósito e mais frio e úmido no final. No local específico da cabeceira de vale, provavelmente associado ao pedoclima mais úmido, espécies arbustivas marcam a transição entre matas-galeria dos vales e campos dos divisores.

c) O depósito turfoso da unidade 2 foi provavelmente afetado por condições de degradação ambiental, implicando erosão nos setores mais elevados da encosta e sedimentação alúvio-coluvial (Unidade 3, na figura 15), compactando e deformando a unidade turfosa.

d) Segue período de estabilidade ambiental durante o qual um horizonte pedológico superficial (A moderado) se desenvolve sobre a unidade 3 (Unidade 4). Esse horizonte foi truncado, posteriormente, pela erosão.

Os resultados obtidos para a seqüência inferior sugerem que o lençol freático esteve posicionado próximo da superfície topográfica, na cabeceira de vale do depósito, que estava então entre 5 e 7 metros abaixo do nível topográfico atual, em período que seria equivalente ao EIM 3. A composição polínica da unidade 2 sugere dois períodos distintos de relativa estabilidade ambiental (Fig. 9 e Fig. 10). O período mais antigo (zona polínica I) parece ter sido mais quente e mais seco do que o período mais recente (zona polínica II). Esses resultados sugerem mudança paleoambiental a partir de período de clima relativamente mais seco e mais quente para período de clima mais frio e mais úmido durante período correlacionável ao interestádio do EIM 3. Os dados isotópicos, por sua vez indicam ambiente globalmente mais úmido durante o desenvolvimento da unidade 2 (ver Fig.11). Conseqüentemente, os resultados obtidos dessa unidade turfosa demonstram que o aumento da umidade local não ocorreu necessariamente associado ao aumento da temperatura, e que períodos de resfriamento da atmosfera não acarretaram necessariamente déficit hídrico. Essas condições ambientais locais podem ser explicadas em função do padrão hidrológico típico das cabeceiras de vale, que propicia concentração e retenção de umidade no solo.

\section{2 - SEQÜÊNCIA INTERMEDIÁRIA: COBERTURA VEGETAL MISTA E SEDIMENTAÇÃO EPISÓDICA NAS PROXIMIDA- DES DOS DIVISORES DE ÁGUA DURANTE O ÚLTIMO MÁ- XIMO GLACIAL (UMG) A interpretação global avançada para os depósitos da seqüência intermediária, descrita na seção pedoestratigráfica de alta encosta (ver Fig. 3), indica a ocorrên- cia de camadas de colúvio pleistocênico alternadas com hori- zontes superficiais de solo, sendo ambas truncadas por fluxos de escoamento superficial concentrado que sugerem mudanças paleoambientais como são resumidas a seguir.}

a) Entre $19 \mathrm{ka} \mathrm{e} 15 \mathrm{ka}$, lentes coluviais paralelas se espalham sobre a encosta, provavelmente sob influência de fluxos gravitacionais difusivos (unidades 5 e 7, da figura 15). 


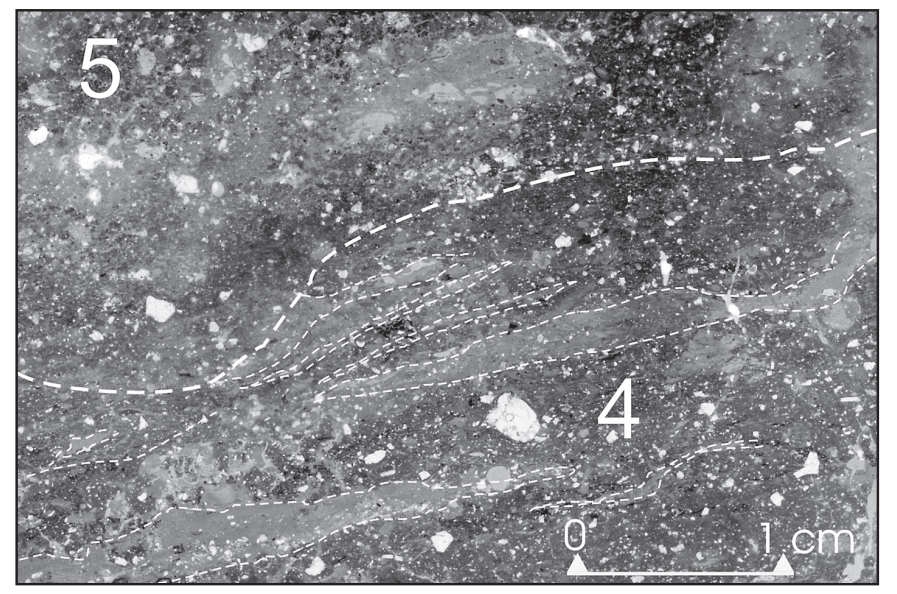

Figura 12 - Imagem digitalizada de lâmina delgada na transição entre as unidades 4 e 5 . Linha tracejada grossa: limite entre unidades 4 e 5. Linhas pontilhadas finas: limites entre lâminas de tração, formadas na unidade 4.

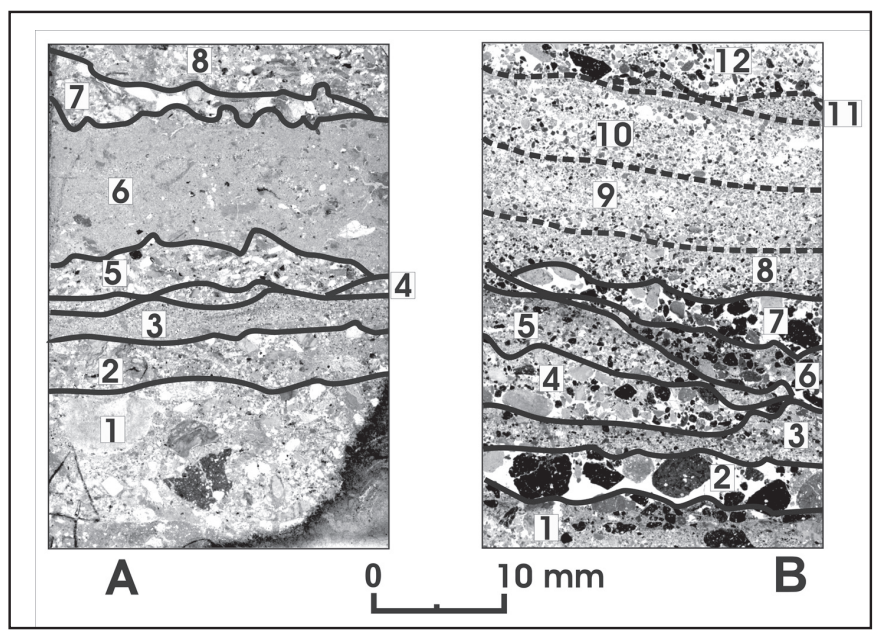

Figura 13 - Imagens digitalizadas de lâminas delgadas da unidade $6(A)$ e de amostra de depósito de escoamento superficial atual (B). Números indicam as diferentes unidades delimitadas nas lâminas

b) Horizontes pedogenéticos superficiais se desenvolvem no último estágio glacial, acumulando espesso horizonte superficial húmico durante o UMG e em torno de $15 \mathrm{ka} \mathrm{A}$. P. (unidades 6 e 8, na figura 15) Embora relativamente mais freqüentes, gramíneas foram transformadas em carbono do solo junto com material orgânico de arbustos e árvores, nas proximidade dos divisores de água (ver Fig.5).

c) Erosão por ravinas e voçorocas afeta o local em período ainda não determinado, após 15 ka A.P. As estruturas de corte e preenchimento criadas indicam mudança do padrão hidrológico anterior, dominado por fluxos gravitacionais difusivos, que agora ocorrem na forma de escoamento superficial concentrado.

Esse registro de alta encosta é interpretado como característico de ambiente local que foi influenciado por relativo superávit de umidade, mesmo durante o Último Máximo Glacial, nas proximidades dos divisores de água. Espessos horizontes húmicos se intercalam com camadas coluviais. Os materiais coluviais, mal selecionados, indicam padrão deposicional característico

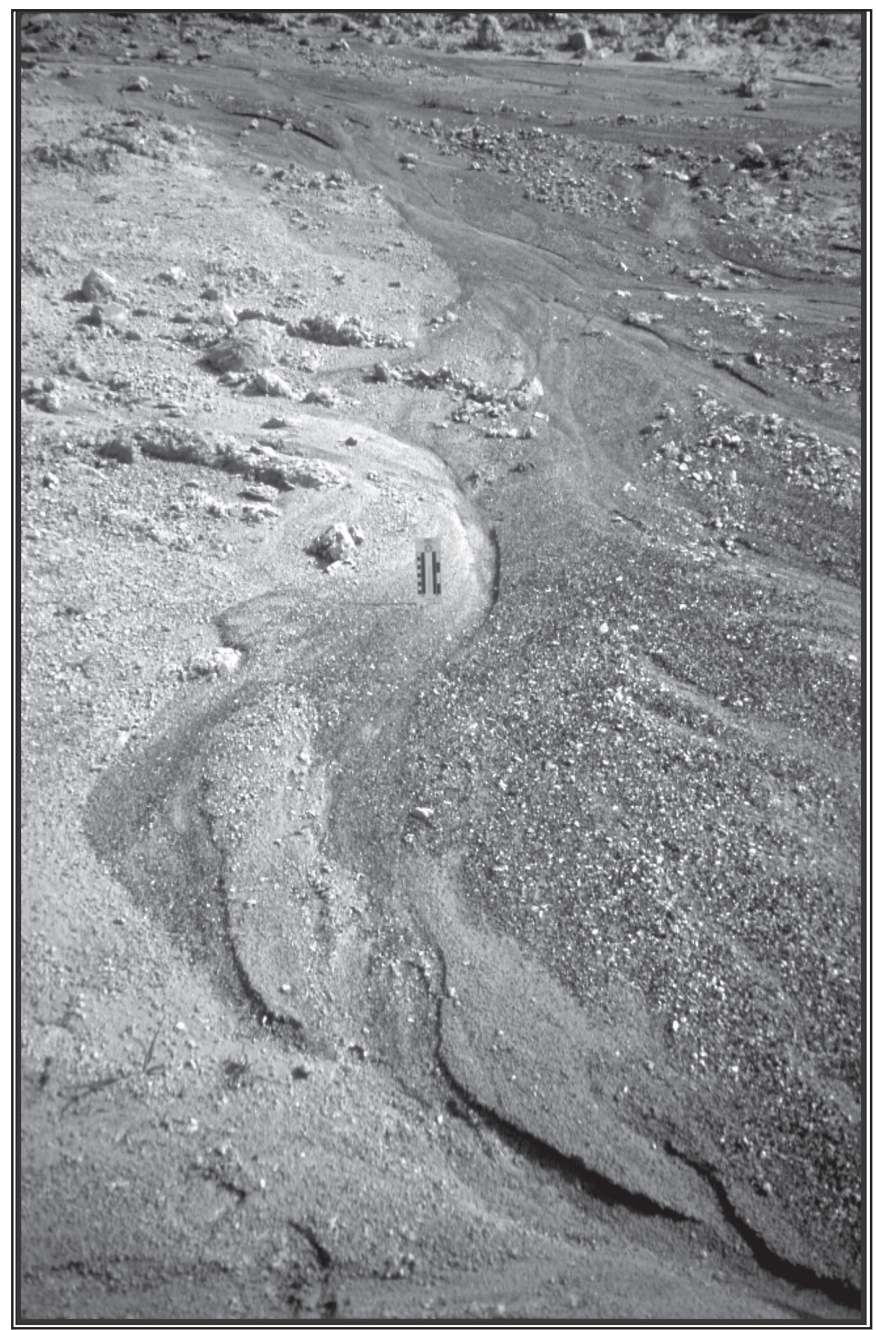

Figura 14 - Depósito atual de escoamento superficial difuso no piso da mina de argila estudada

da chamada fácies de piemonte (Oliveira \& Lima 2004). Esse padrão evolutivo foi alterado após 15 ka A.P., implicando escoamento superficial concentrado e erosão por ravinas e voçorocas, em período de provável aumento da umidade atmosférica.

3 - SEQÜENNCIA SUPERIOR: RAREFAÇÃO DA VEGETAÇÃO, ESCOAMENTO TORRENCIAL E AGRADAÇÃO DE CABECEIRAS DE VALE DURANTE O HOLOCENO MÉDIO A seqüência superior é composta principalmente por depósitos de fluxos torrenciais sobre encosta, soterrando a cabeceira de vale quaternária que se situava então a aproximadamente 3 metros abaixo do nível topográfico atual. A análise da seqüência superior indica agradação local através de acumulação alúviocoluvial (ver Fig. 6).

A seqüência inicia com o truncamento da unidade subjacente durante o Holoceno Médio. Após esse evento, pulsos de sedimentação geram depósito constituído por lentes alúvio-coluviais finamente estratificadas (Unidades 10, 11 e 12, na figura 15). A comparação entre estruturas microscópicas holocênicas e atuais, criadas sobre superfícies degradadas, sugere a atuação do escoamento superficial no Holoceno Médio, afetando superfícies topográficas desprovidas de vegetação densa. O padrão multiepisódico desse depósito holocênico, comparável ao de amostra atual, é interpretado como evidência de clima relativamente mais seco durante o Holoceno Médio, provavelmente associado a regime climático com longa estação seca. $\mathrm{O}$ depósito teria sido 


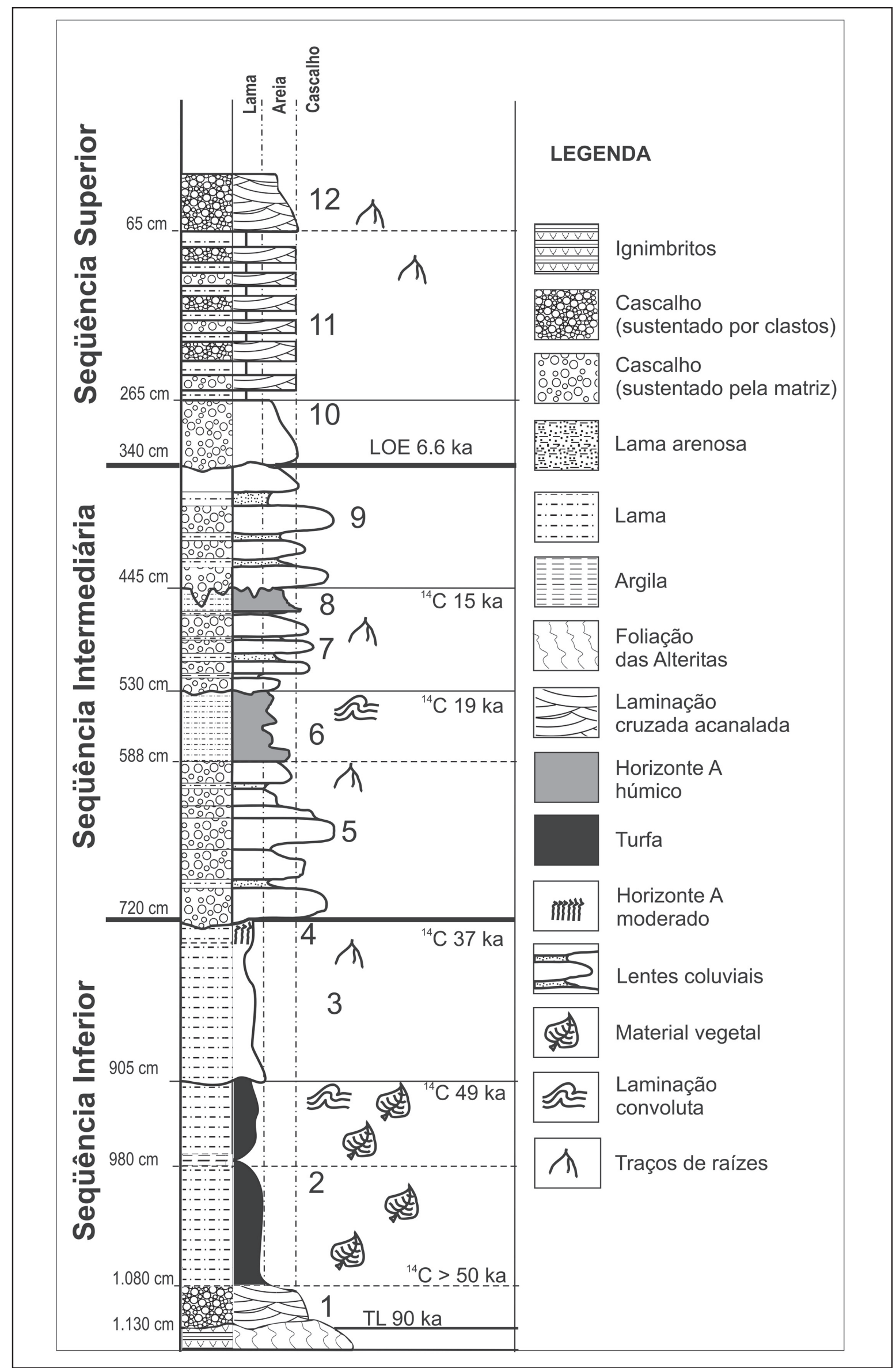

Figura 15 - Seção colunar sintética das duas seções pedoestratigráficas do estudo, definindo: Seqüência Inferior (depósitos e solos correlacionáveis ao EIM 3, ou a períodos mais remotos); Seqüência Intermediária (depósitos e solos do UMG); Seqüência Superior (depósitos do Holoceno Médio). 


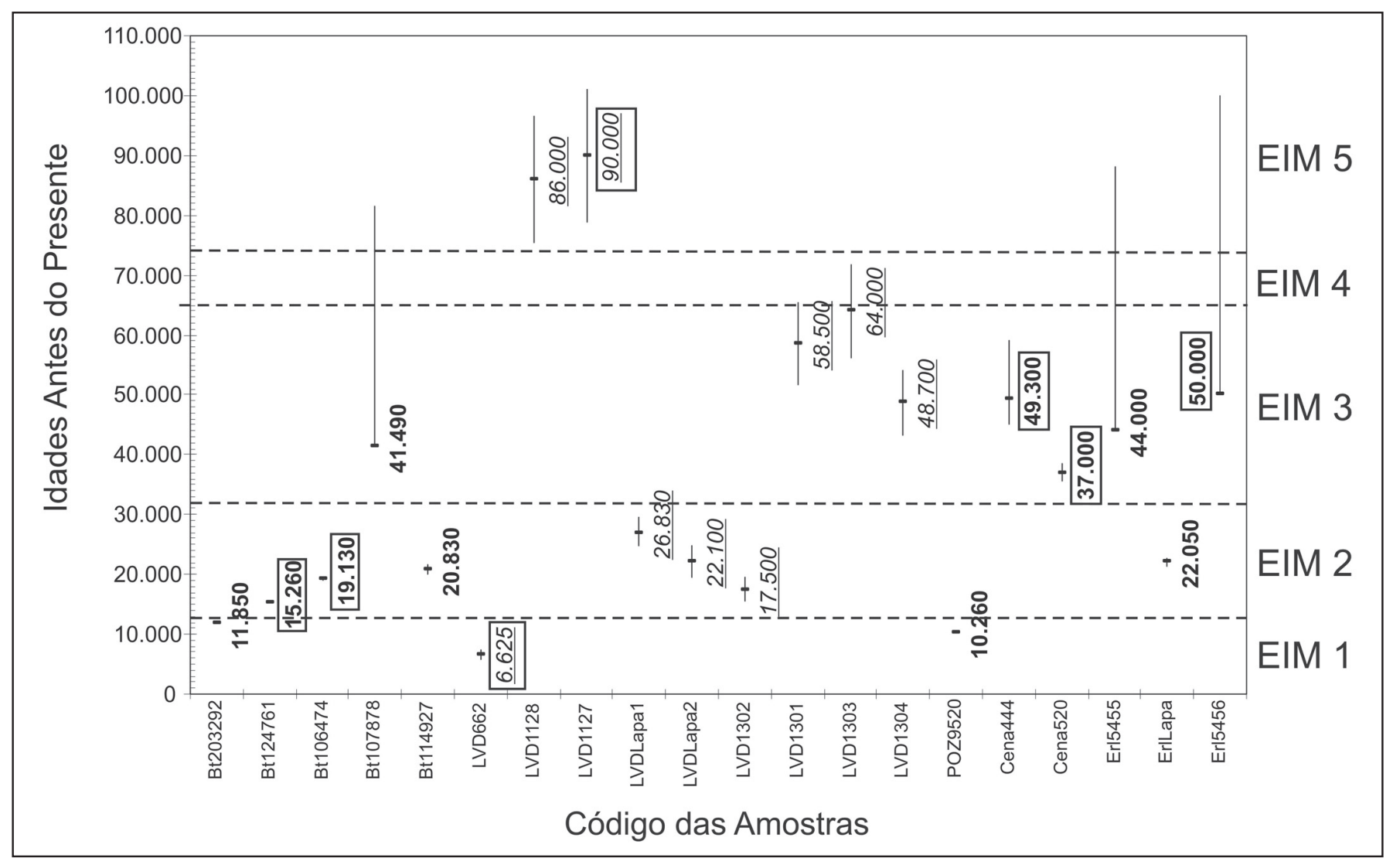

Figura 16 - Datações obtidas no Sul do Brasil. Idades grafadas em negrito correspondem a datações ${ }^{14}$ C. Idades em itálico e sublinhadas correspondem a datações TL e LOE. As idades delimitadas por retângulos correspondem às datações consideradas neste trabalho. Fontes: (Oliveira et al. 2001; Camargo 2005; Camargo Filho 2005; Fett Júnior 2005)

criado sob o efeito de pulsos de escoamento superficial sobre encostas desprovidas de vegetação densa.

4 - ZONAS DE SATURAÇÃO, FONTES DE ESCOAMENTO SUPERFICIAL E MODIFICAÇÃO DO RELEVO AO FINAL DO PLEISTOCENO E NO HOLOCENO MÉDIO Os resultados deste estudo sugerem que a evolução do relevo local foi marcada por episódios de pedogênese e de morfogênese que coincidem com eventos associados a mudanças climáticas globais e hemisféricas (Blunier et al. 1998). As datações obtidas pelo ${ }^{14} \mathrm{C}$ coincidem com períodos durante os quais horizontes superficiais húmicos, turfosos e hidromórficos se desenvolveram na área do estudo, no final do Pleistoceno. Mudanças climáticas globais e hemisféricas (Blunier \& Brook 2001, Clark et al. 2002, Weaver et al. 2003) e registros polínicos independentes (Behling \& Hooghiemstra 2001, Behling 2002, Behling et al. 2004) sugerem que naquele período o Sul do Brasil se encontrava sob a influência de temperaturas médias inferiores às atuais.

Em geral, aceita-se que períodos de resfriamento global da atmosfera (estádios glaciais) implicariam clima mais seco, ou mesmo árido, em áreas tropicais e subtropicais, enquanto períodos de aquecimento global (estádios interglaciais e interestádios) implicariam clima mais úmido. Entretanto, esse modelo bipolar (frio/seco; quente/úmido) é difícil de ser aplicado aos resultados expostos neste trabalho. De fato, paleossolos húmi$\cos$, turfosos e hidromórficos não poderiam desenvolver-se na área de estudo, no período em foco, em ambiente marcado apenas pelo predomínio de déficit hídrico acentuado. Esses solos necessitam de condições de saturação por água durante vários meses ao ano para desenvolver-se (Shotyk 1992). Como as seqüências pedoestratigráficas estudadas se desenvolveram sobre mantos de alteração profundos, distantes do substrato rochoso menos permeável, a existência de zonas de saturação superficiais nas cabeceiras de vale deve ser atribuída, principalmente, a: a) à configuração topográfica; b) ao ambiente local relativamente úmido; c) às baixas temperaturas e, sobretudo, d) às taxas de evaporação relativamente baixas.

Conseqüentemente, as idades estimadas para o desenvolvimento dos paleossolos identificados nas áreas do estudo sugerem o predomínio de condições climáticas locais relativamente úmidas, mesmo durante os períodos mais frios do último estágio glacial. Essa condição de solos locais com horizontes superficiais saturados por água deve ser considerada ainda como o principal fator de manutenção do escoamento superficial como agente efetivo e recorrente ao longo do tempo. Com efeito, a existência de zonas de saturação próximas da superfície explica de forma satisfatória a dinâmica alternada, salientada ao longo do trabalho, de períodos de morfogênese e de pedogênese nas cabeceiras de vale. Esse superávit local de umidade teria implicado desenvolvimento anaeróbico do solo durante os períodos de estabilidade ambiental e erosão e sedimentação relacionada ao escoamento superficial e a movimentos de massa durante transições entre estádios e interestádios do final do Pleistoceno.

De sua parte, o registro holocênico também apresenta evidências de que o escoamento superficial teria atuado como importante agente morfodinâmico, erodindo formações superficiais desprovidas de cobertura vegetal densa no Holoceno Médio. Mudanças da composição da vegetação, em diferentes locais, sugerem que essa modificação das condições paleoambientais holocênicas nos planaltos do Sul do Brasil teve caráter regional (Behling 1997), indicando paleoclima holocênico marcado por longo período de estação seca. A ocorrência de déficit hídrico 
pronunciado durante o Holoceno Médio é apontada ainda para algumas áreas do sudeste e do centro-oeste do Brasil, nas quais se verificou, através de isótopos do carbono e da análise de carvão dos solos, maior freqüência de incêndios entre 6.000 e 3.000 anos A.P. (Gouveia et al. 2002, Pessenda et al. 2004).

A possibilidade de existência de clima holocênico marcado por regime climático com longa estação seca no Sul do Brasil explica, de forma satisfatória, a interpretação sedimentológica e micromorfológica que foi avançada para o registro da Seqüência Superior deste estudo, segundo a qual o escoamento superficial teria atuado sobre superfícies geomorfológicas desprovidas de cobertura vegetal densa durante o Holoceno Inferior e Médio.

No geral, com base tanto no registro pleistocênico quanto no holocênico, as interpretações paleoidrológicas avançadas para a área do estudo ressaltam a definição de cabeceiras de vale como fontes para a formação do escoamento superficial, que aparenta ser o principal agente de modificação do relevo na área do estudo. Nessas cabeceiras, lençóis confinados que dão origem aos escoamentos superficiais difuso e concentrado seriam os principais agentes que teriam condicionado tanto a pedogênese quanto a morfogênese ao final do Pleistoceno e no Holoceno Médio (ver Fig. 2).

CONCLUSÕES Os resultados apresentados revelam registros importantes de adaptações de cabeceiras de vale a mudanças ambientais datadas do final do Pleistoceno e do Holoceno Médio. Destacam-se, em primeiro lugar, os seguintes resultados sedimentológicos: a) evidências de sedimentação e de pedogênese durante o UMG, raras em áreas tropicais e subtropicais, revelando mudanças de padrão hidrológico local; b) evidências de ocorrência de clima com estação seca prolongada durante o Holoceno-Médio, com conseqüências ambientais de caráter paleontológico e arqueológico que ultrapassam o escopo deste trabalho; c) evidências de predomínio do escoamento superficial como principal agente morfogenético entre o EIM 3, pelo menos, e o Holoceno. Em segundo lugar, destacam-se resultados associados a dados representativos (proxy data) que ressaltam: a) evidências de vegetação mista localizada nas proximidades de divisores de água durante o UMG; b) registro polínico, isotópico e sedimentológico, sugerindo que o binômio clássico "clima quente e úmido X clima frio e seco" não se ajusta à área do estudo, na qual períodos de resfriamento se associam a ambiente local relativamente úmido e períodos de aquecimento coincidem com evidências de déficit hídrico.

Por fim, ressalta-se a interpretação paleoambiental geral avançada com base nesses registros, segundo a qual estádios glaciais implicariam climas mais secos do que o atual, porém com temperaturas e taxas de evaporação também mais baixas, gerando relativo superávit local de umidade armazenado como água do solo nas proximidades de cabeceiras de vale. Nessas áreas, zonas de saturação próximas da superfície tenderiam a expandir-se nas transições entre estádios glaciais, interglaciais e interestádios, independente do sinal da mudança climática, durante os períodos de adaptação do sistema às mudanças ambientais, aumentando a contribuição das zonas de saturação para a formação do escoamento superficial e causando erosão e sedimentação local sobre superfícies geomorfológicas.

Agradecimentos Este trabalho foi realizado com o apoio do Conselho Nacional de Desenvolvimento Científico e Tecnológico (CNPq) e do Programa de Pós-Graduação em Geografia da Universidade Federal de Santa Catarina.

\section{Referências}

Behling H. 1997. Late Quaternary vegetation, climate and fire history in the Araucaria forest and campos region from Serra Campos Gerais (Paraná), S. Brazil. Review of Palaeobotany and Palynology, 97:109-121.

Behling H. 2002. South and Southeast Brazilian grasslands during Late Quaternary times: a synthesis. Palaeogeography, Palaeoclimatology, Palaeoecology, 177:19-27.

Behling H. \& Hooghiemstra H. 2001. Neotropical savanna environments in space and time: Late Quaternary interhemispheric comparisons. In: V. Markgraf (ed.) Interhemispheric Climate Linkages. Academic Press, San Diego, CA, pp.: 307-323.

Behling H., Pillar V., Orlóci L., Bauermann S.G. 2004. Late Quaternary Araucaria forest, grassland (Campos), fire and climate dynamics, studied by high resolution pollen, charcoal and multivariate analysis of the Cambará do Sul core in southern Brazil. Palaeogeography, Palaeoclimatology, Palaeoecology, 203:277-297.

Bertran P. \& Jomelli V. 2000. Post-glacial colluvium in western Norway: depositional processes, facies and palaeoclimatic record. Sedimentology, 47:1053-1068.

Bertran P. \& Texier J.P. 1999. Facies and microfacies of slope deposits. Catena, 35:99- 121.

Biondi J.C., Bartoszek M.K., Vanzela G.A. 2001. Controles geológicos e geomorfológicos dos depósitos de caulim da bacia de Campo Alegre (SC). Revista Brasileira de Geociências, 31:13-20.

Blunier T. \& Brooks E.J. 2001. Timing of millennial-scale climate change in Antarctica and Greenland during the Last Glacial period. Science, 291:109-112.

Blunier T., Chappellaz I., Schwander I., Dallenbach A., Stauffer B., Stocker T.F., Raynaud D., Jouzel I., Clausen H.B., Hammer C.U., Johnsen S.J. 1998. Asynchrony of Antarctica and Greenland climate during the last glacial, Nature, 394:739-734.

Bullock P., Fedoroff N., Jongerius A., Stoops G., Tursina T. 1985. Han- dbook of soil thin section description. Waine Research, Albrington, $152 \mathrm{pp}$.

Camargo Filho M. 2005 - O significado paleoambiental de seqüencia pedossedimentar em baixa-encosta: o caso dos paleossolo Monjolo, Lapa, Pr. Tese de doutoramento, Departamento de Geociências, Universidade Federal de Santa Catarina, 325 p.

Camargo G. 2005 - O significado paleoambiental de depósitos de encosta e de preenchimento de canal no municipio de Lapa, no sul do Segundo Planalto Paranaense. Tese de Doutoramento, Departamento de Geociências, Universidade Federal de Santa Catarina, 302 p.

Clark P.U., Mitrovica J. X., Milne G. A., Tamisiea M. E. 2002. Sea- Level Fingerprinting as a direct test for the source of Global Meltwater Pulse IA. Science, 295: 2438-2441.

Cosandey C. \& Oliveira M.A.T. 1996. Surfaces saturées, surfaces contributives: localisation et extension dans l'espace du bassin versant. Hydrological Sciences, Journal des Sciences Hydrologiques, 41:751-761.

De Keyser T.L. 1999. Digital scanning of thin sections and peels. Journal of Sedimentary Research, 69:962-964.

Delvigne J. 1998. Atlas of Micromorphology of Mineral Alteration and Weathering. The Canadian Mineralogist, Special publication 3, Mineralogical Association of Canadá and ORSTOM Éditions, Canadá, $494 \mathrm{p}$.

Dietrich W.E. \& Dunne T. 1993. The channel head. In: K. Beven, M.J. Kirkby (eds) Channel network hydrology. John Wiley and Sons, New York, pp.: 175-219.

Fett Júnior N. 2005. Aspectos morfológicos, estratigráficos e sedimentológicos de depósitos quaternários no curso médio do Rio Pardo (municipio de Candelária, RS). Dissertação de Mestrado, Departamento de Geociências, Universidade Federal de Santa Catarina, 146 p.

Fitzpatrick E.A. 1984. Micromorphology of Soils. Chapman and Hall, NewYork, 433 p. 
Flemming B.W. 2000. A revised textural classification of gravel-free muddy sediments on the basis of ternary diagrams. Continental Shelf Research, 20:1125-1137.

Folk R.L. 1974. The petrology of sedimentary rocks. Hemphill Publishing Co., Austin, 182 p.

Gouveia S.E.M., Pessenda L.C.R., Aravena R., Boulet R., Scheel-Ybert R., Bendassoli J. A., Ribeiro A.S., Freitas H.A. 2002. Carbon isotopes in charcoal and soils in studies of paleovegetation and climate changes during the late Pleistocene and the Holocene in the southeast and centerwest regions of Brazil. Global and Planetary Change, 33:95-106.

Grimm E.C. 1987. Coniss: a Fortran 77 program for stratigraphically constrained cluster analysis by the method of the incremental sum of squares. Computer and Geosciences, 13: 13-35.

Lima G.L. 2005. Caracterização pedoestratigráfica de depóstios de encosta e de vale, localidade de Cerro do Touro, Campo Alegre, Estado de Santa Catarina. Dissertação de Mestrado, Departamento de Geociências, Universidade Federal de Santa Catarina, 125 p.

Meis M.R.M. \& Machado M.B. 1978. A morfologia de rampas e terraços do Médio Vale do Rio Doce. Finisterra, 13:201-218.

Meis M.R.M. \& Moura J.R.S. 1984. Upper Quaternary Sedimentation and Hillslope Evolution: Southeastern Brazilian Plateau. American Journal of Science, 284:241-254.

Melo M.S. \& Cuchierato G. 2004. Quaternary colluvial-eluvial covers of the Eastern Paraná Basin, Southeastern Brazil. Quaternary International, 114:45-53.

Modenesi-Gauttieri M. C. 2000. Hillslope deposits and the Quaternary evolution of the Altos Campos - Serra da Mantiqueira, from Campo do Jordão to the Itatiaia Massif. Revista Brasileira de Geociências, 30:504-510.

Nemec W. \& Kazanci N. 1999. Quaternary colluvium in west-central Anatolia: sedimentary facies and palaeoclimatic significance. Sedimentology, 46:139-170.

Oliveira M.A.T. \& Ferreira G.M.S.S. 2004. Descrição micromorfológica de estruturas sedimentares em colúvios e aluviões recentes. In: SBG, Congresso Brasileiro de Geologia, 42, Anais, p. 985-987.

Oliveira M.A.T. \& Lima G.L. 2004. Classificação de sedimentos quaternários em cabeceiras de vale através da aplicação do diagrama de Flemming: município de Campo Alegre, Norte de Santa Catarina. Geociências, 23:67-78.

Oliveira M.A.T., Camargo G., Paisani J.C., Camargo Filho M. 2001. Caracterização paleohidrológica de estruturas sedimentares quaternárias através de análises macroscópicas e microscópicas: do registro sedimentar local aos indícios de mudanças globais. Pesquisas em Geociências, 28:183-195.

Pessenda L.C.R., Gouveia S.E.M., Aravena R., Boulet R., Valencia E.P.E. 2004. Holocene fire and vegetation changes in southeastern Brazil as deduced from fossil charcoal and soil carbon isotopes. Quaternary
International, 114(9):5-43.

Sant'Ana W.O., Oliveira M.A.T., Lima G.L., Ferreira G.M.S.S., Paulino R.B. 2005. Aplicação da micromorfologia de solos na identificação de soterramento de paleossolo Quaternário. In: Congresso da Abequa, 10, Guarapari, Atas, p. 1-6.

Scholle P.A. 1979. A colour illustrated guide to constituents, textures, cements and porosities of sandstones and associated rocks. Tulsa, American Assocition of Petroleum Geologists, Memoir 28, 201 p.

Servant M., Soubiès F., Suguio K., Turcq B., Fournier M. 1989. Alluvial fans in Southeastern Brazil as an evidence for early Holocene dry climate period. In: International Symposium on Global Changes in South America During the Quaternary, Special Publication, v.1, p. 75-77.

Shotyk W. 1992. Organic soils. In: I.P. Martini, W. Chesworth (eds.) Weathering, Soils and Paleosoils. Developments in Earth Surface Processes 2, Elsevier, pp.: 203-224.

Stevaux J. C \& Santos M. L. 1998. Palaeohydrological changes in the Upper Paraná River, Brazil, during the late Quaternary: a facies approach. In: G. Benito, V. R. Baker, K.J. Gregory (eds) Palaeohydrology and Environmental Change. John Wiley and Sons, Chichester, pp.: 273-285.

Sugden D. E., Bentley M. J., Fogwill C. J., Hulton N. R. J., McCulloch R. D., Purves R. S. 2005. Late-glacial glacier events in southernmost South America: a blend of "northern" and "southern" hemispheric signals? Geografiska Annaler, 87A: 273-288.

Thomas M. F. \& Thorp M. B. 1996. The response of geomorphic syste$\mathrm{ms}$ to climate and hydrological change during the Late Glacial and early Holocene in the humid and sub-humid tropics. In: J. Branson, M.F. Thomas, J. Nott, D.M. Price (eds) Global Continental Changes: the Context of Palaeohydrology. Geological Society Special Publication, 115, pp.: 139-153.

Thomas M.F., Nott J., Price D.M. 2001. Late Quaternary sedimentation in the humid tropics: a review with new data from NE Queensland, Australia. Geomorphology, 39:53-68.

Turcq B., Pressinotti M. N., Martin L. 1997. Paleohydrology and paleoclimate of the past 33,000 years at the Tamanduá river, Central Brazil. Quaternary Research, 47:284-294.

Weaver A.J., Saenko O.A., Clark P.U., Mitrovica J.X. 2003. Meltwater Pulse 1A from Antarctica as a Trigger of the Bølling-Allerød Warm Interval. Science, 299:1709-1713.

Wilson R.C.L., Drury S.A., Chapman J.L. 2000. The great ice age. Routledge, London, $267 \mathrm{pp}$. 